\title{
CONTEXTO DA DISCRIMINAÇÃO FEMININA NO BRASIL E LEGITIMAÇÃO DAS MEDIDAS AFIRMATIVAS DE GÊNERO
}

Ana Paula Oliveira Ávila ${ }^{1}$

Paula Vilela Machado de Souza ${ }^{2}$

\begin{abstract}
Resumo
O presente trabalho busca analisar dados que justificam a adoção de cotas para mulheres no âmbito empresarial e político brasileiro, como outras medidas de combate às iniquidades de gênero. As desigualdades originadas do modelo de sociedade que tem por regra o masculino foram debatidas historicamente pelas correntes do movimento feminista, vertendo-se o debate em instrumentos jurídicos de promoção da igualdade de direitos. Diante da persistência das desigualdades de remuneração, divisão do trabalho doméstico e autonomia, surgem práticas e políticas públicas que buscam a igualdade material por meio da maior inserção feminina nos locais de trabalho e na política. Contudo, qualquer reflexão sobre as críticas que costumam ser dirigidas à adoção de cotas pressupóe o entendimento do contexto que lhe dá causa e legitima, justamente o que se pretende apresentar por meio desta pesquisa.
\end{abstract}

Palavras-chave: Feminismo; Discriminação de Gênero; Igualdade; Ações Afirmativas; Cotas para Mulheres.

\section{INTRODUÇÃO}

As desigualdades pautadas pelo critério de gênero seguem em pleno debate no âmbito dos movimentos sociais e feministas. O surgimento mais visível desses movimentos remonta ao contexto da Revolução Francesa, no qual se exteriorizavam na luta por tratamento igualitário e justo às mulheres, visando sua independência intelectual, participação política por meio do voto, exercício de trabalho remunerado e outras demandas conquistas que vem se dando lenta e progressivamente ao longo de todos esses anos.

Algumas conquistas foram alcançadas por meio de proteção legal que garante a igualdade universal e também em leis e convenções específicas acerca dos direitos das mulheres. Expoente dessas conquistas é a Convenção sobre a Eliminação de Todas as Formas de Discriminação contra a Mulher - CEDAW, de 1979. No

\footnotetext{
${ }^{1}$ Doutorado em Direito pela UfRGS (2007). Professora Titular de Direito Constitucional e Direito Econômico dos Cursos de Graduação e Mestrado - UniRitter (Porto Alegre). Coordenadora do Programa de Pós-Graduação Stricto Sensu - Mestrado em Direito do UniRitter (Porto Alegre). Diretora Adjunta da Escola Superior de Advocacia da OAB/RS. E-mail: anapaula.avila@icloud.com

${ }^{2}$ Pesquisadora do Grupo de Estudos "Direito da antidiscriminação, igualdade e diferença". Pós-Graduanda na UniRitter. E-mail: paulavmsouza@gmail.com
} 
plano interno, a legislação brasileira também se ocupou de tais questões tanto em nível constitucional, onde a igualdade entre homens e mulheres é explícita no art. 5º inc. II, como em nível infraconstitucional, onde a igualdade material vem sendo reforçada por normas protetivas dos direitos das mulheres.

O reconhecimento de tais garantias e o debate sobre as desigualdades de gênero convivem com valores culturais e regras sociais que têm como base um referencial masculino e branco, o que explica em certa medida o preconceito ainda existente contra a mulher e contra a manifestação de sua autonomia. As relações sociais construídas com base no gênero e permeadas pela discriminação envolvem fatores culturais que legitimam e reforçam o status quo de uma sociedade baseada no padrão masculino, especialmente mediante estereótipos e ideologias que submetem a mulher a uma categoria inferior ao homem. Esse preconceito, cuja demonstração é ora explícita ora velada, ocorre em especial nas relações de trabalho e na inserção das mulheres na arena política, num fenômeno presente não só no Brasil como ao redor do mundo.

A discriminação foi conceituada pelas convenções internacionais no âmbito da $\mathrm{ONU}$, e são diversos os diplomas normativos, internacionais e internos, na expectativa de que as nações adotem as ações necessárias à efetivação da plena igualdade de direitos. No entanto, socialmente o preconceito manifesta-se de múltiplas maneiras, como discriminação direta, indireta, institucional e interseccional, cabendo identificá-las em função das características únicas de cada tipo, uma vez que isso reflete nas medidas de combate à discriminação que levem a uma sociedade mais justa e igualitária.

É certo que a própria legislação serve como mecanismo de prevenção e recriminação da discriminação latente, porém, cada vez que se edita uma norma protetiva de cunho específico em favor das mulheres, ressurgem as discussões em torno da legitimidade ou da necessidade da medida dotada - basta lembrar, neste particular, que a própria Lei Maria da Penha precisou ter sua constitucionalidade confirmada pelo Supremo Tribunal Federal na ADC 19 para ter sua aplicabilidade assegurada. Daí o problema que inspira a presente pesquisa: responder se tais medidas protetivas possuem uma causa legítima e se são adequadas e necessárias para o combate à discriminação. Isso pressupõe compreender o ambiente em que se insere a discriminação feminina no Brasil para, então, refletirmos sobre os fatores que justificam e legitimam o uso de ações afirmativas em defesa das mulheres, mais especificamente na modalidade de cotas. Essas ações, tradicionalmente utilizadas para reparar iniquidades de raiz racial, também podem servir à causa da equidade de tratamento às mulheres.

Assim, o objetivo deste trabalho é analisar o contexto em que se inserem algumas ações afirmativas com base no gênero, avaliando a necessidade da adoção de medidas com este foco no Brasil. Para a consecução deste objetivo -e lançando mão do método dedutivo, amparado por revisão bibliográfica, documental e legislativa-, apresenta-se inicialmente um breve histórico da luta contra a discriminação feminina e seu impacto na legislação internacional e brasileira. Em seguida, analisam-se as diferentes formas de discriminação contra as mulheres, 
descrevendo-se o atual cenário da desigualdade em relação à mulher, com foco no mercado de trabalho e no espaço político. Esses dois aspectos foram selecionados para, em sede de conclusão, refletirmos sobre os fundamentos que justificam as políticas públicas em discussão no Brasil, notadamente as cotas previstas na Lei nº 9.504/1997, no âmbito político, e no Projeto de Lei no 112/2010, em tramitação no Senado Federal, que busca fixar a progressiva reserva de vagas para mulheres em conselhos deliberativos de empresas que a União detenha majoritária ou exclusivamente.

\section{A LUTA HISTÓRICA CONTRA A DISCRIMINAÇÃO FEMININA}

O feminismo, como movimento político e intelectual, surge no final do séc. XVIII para o século XIX, como reflexo da Revolução Francesa, manifestando-se por várias correntes - como, mas não somente, o feminismo liberal, negro e contemporâneo. Caracterizou-se pelo pensamento crítico a respeito da submissão da mulher em relação ao homem e das causas e mecanismos de reprodução da dominação masculina, buscando compreender as desigualdades de gênero e seus reflexos nas esferas pública e privada. ${ }^{3}$

Uma das expoentes no âmbito da Revolução Francesa foi Olympe de Gouges (pseudônimo utilizado por Marie Gouze), devido ao seu engajamento no movimento feminista e pela apresentação da "Declaração dos Direitos da Cidadã” à Assembleia Nacional Francesa - uma elaboração textual voltada para o feminino, tendo como base a "Declaração dos Direitos do Homem e Cidadão". Nela há, em síntese, a defesa da igualdade de direitos para o homem e a mulher, reivindicação de participação política e distribuição de empregos. Muito embora a possibilidade das mulheres adentrarem a esfera pública, não lhes era garantido o direito à manifestação. ${ }^{4}$

Essa primeira fase do feminismo centrava sua luta em temas como acesso à educação, direito ao voto e igualdade no matrimônio, defendendo a igualdade geral de direitos. Contudo, a sociedade ainda aderia a um modelo convencional de desigualdade fundamentada na vocação "natural" da mulher, concentrando seu discurso na feminilidade e maior sensibilidade das mulheres nos papéis de mãe e esposa, pois seu propósito principal ainda seria servir ao homem e à família. ${ }^{5}$

\footnotetext{
${ }^{3}$ MIGUEL, L. F. O Feminismo e a Política. In: MIGUEL, L. F., BIROLI, F. Feminismo e política: uma introdução. 1aed. São Paulo: Bomtempo, 2014. p.19-20.

${ }^{4}$ ANDREUCCI, A. C. P. T. Igualdade de gênero e ações afirmativas: desafios e perspectivas para as mulheres brasileiras pós Constituição Federal de 1988. São Paulo: LTR, 2012. pg. 41-43. Colaciona-se desta obra, ainda, a transcrição de alguns artigos da referida "Declaração dos Direitos da Cidadã": art. 1 A mulher nasce livre e tem os mesmos direitos do homem. As distinções sociais só podem ser baseadas no interesse comum. Art. 2० O objeto de toda associação política é a conservação dos direitos imprescritíveis da mulher e do homem. Esses direitos são a liberdade, a propriedade, a segurança e, sobretudo, a resistência à opressão. [... ] Art. $6^{\circ} \mathrm{A}$ lei deve ser a expressão da vontade geral. Todas as cidadãs e cidadãos devem concorrer pessoalmente ou com seus representantes para a sua formação; ela deve ser igual para todos. Todas as cidadãs e cidadãos, sendo iguais aos olhos da lei devem ser igualmente admitidos a todas as dignidades, postos e empregos públicos, segundo as suas capacidades e sem outra distinção a não ser suas virtudes e seus talentos.

${ }^{5}$ MIGUEL, L. F., BIROLI, F. Feminismo e política: uma introdução. 1aed. São Paulo: Boitempo, 2014. p.15-21; e ANDREUCCI,
} vol.10, no. 03, Rio de Janeiro, 2017.pp. 1610-1632 
Com as transformações proporcionadas pela Revolução Industrial nos séculos XVIII e XIX, em especial na transição à sua segunda fase (1860-1900) exigindo a produção em larga escala e correlato escoamento de mercadorias, deu-se a inserção da mão de obra feminina. A atividade feminina, entretanto, tinha a característica de ser menos custosa e produtiva do que a masculina, e as mulheres enfrentavam jornadas extenuantes e constante

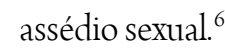

O feminismo, nesse momento chamado de feminismo liberal, embora postulasse igualdade de direitos em sentido similar ao movimento inicial, sofreu críticas pela manutenção do viés de classe e por deixar de lado a questão da escravidão. Isso não se deu em relação a todos os seus autores e defensores, já existindo conexões feitas a respeito da representação política das mulheres e dos operários desde seu início. Destacam-se, nos EUA, líderes sufragistas que defendiam a abolição da escravidão, entre elas Elizabeth Cady Stanton (1815-1902) e Susan B. Anthony (1820-1906), e o estabelecimento de uma comparação entre escravidão negra e a escravidão feminina, por Harriet Taylor Mill (1807-1858 ${ }^{7}$ - mais um convite à reflexão sobre a discriminação feminina.

As feministas negras, por sua vez, apresentam uma face da discussão não enfrentada, problematizando a pretensa identidade genérica da mulher apresentada pelo movimento - no qual suas protagonistas seriam mulheres brancas de classe média, com melhor acesso à educação e em situação mais privilegiada. Foi defendido, nesse contexto, que a experiência das mulheres negras, em condição social distinta, não estava representada na identidade vigente, destacando que sofriam as opressões tanto pelo gênero, como pela raça e ambos, mas mais fortemente o segundo, com reflexos em sua posição social. Objetivou-se, assim, dar atenção a essa perspectiva das mulheres negras e sua respectiva inclusão na pauta feminista. ${ }^{8}$

No século XX chega-se ao momento em que a pauta inicial das reivindicações femininas foi em grande parte alcançada, ao menos formalmente. O direito ao voto foi alcançado nas primeiras décadas; o acesso das mulheres ao ensino, inclusive superior, torna-se comum e os códigos civis incluem a igualdade entre os cônjuges. O feminismo contemporâneo, então, concentra seus questionamentos na superação do paradigma social do gênero feminino, pelo qual, segundo Andreucci [acerca da elaboração teórica de Simone de Beauvoir],

$[\ldots]$ o papel social da mulher era um estereótipo construído por homens e até mesmo por mulheres que aceitavam a sua condição de "naturalmente" ser mulher. Seres submissos que nasciam e cresciam para cumprir papéis moldados historicamente pelos soberanos, considerados o primeiro sexo, detentor absoluto do conhecimento, da educação e "proprietário" das mulheres, fossem elas esposas, filhas, irmãs. Eram o segundo frágil, o

A. C. P. T. Igualdade de gênero e ações afirmativas: desafios e perspectivas para as mulheres brasileiras pós Constituição Federal de 1988. São Paulo: LTR, 2012.pg. 41-43.

${ }^{6}$ ANDREUCCI, op. cit. pg.43- 46.

${ }^{7}$ MIGUEL, L. F. O Feminismo e a Política. In: MIGUEL, L. F., BIROLI, F. Feminismo e política: uma introdução. 1ªd. São Paulo: Boitempo, 2014.p.22.

${ }^{8}$ MIGUEL, L. F. A Identidade e a Diferença. In: MIGUEL, L. F, BIROLI, F. Feminismo e política: uma introdução. laed. São Paulo: Boitempo, 2014. p.85-89. 
segundo sexo. ${ }^{9}$

Busca-se, portanto, discutir os mecanismos pelos quais a construção desse paradigma se molda e se perpetua, bem como os limites dos papéis sociais fixados e a sua repercussão na esfera de atuação feminina. Além disso, sucintamente, pode-se dizer que

a objetificação da mulher, a negação de seu potencial de transcendência e sua fixação perene no mundo da natureza (a ser contida pela cultura), bem como o fato de que ela é permanentemente levada a se ver pelos olhos dos homens, são das constatações que orientam a crítica feminista à submissão das mulheres nas sociedades ocidentais. ${ }^{10}$

Resumidamente, percebe-se que as elaborações teóricas vão, no seu início, desde a defesa por igualdade em caráter mais absoluto, chegando à discussão acerca das peculiaridades das várias experiências femininas, até ao questionamento da maneira como o conceito gênero é socialmente construído. Essa breve cronologia, traçada para evidenciar as demandas femininas ao longo dos anos, demonstra a multiplicidade de fatores envolvidos além do sexo, posteriormente tratado como gênero - tais como raça, classe e posição social -, sem pretensão de esgotálos, mas servindo para contextualizar as dificuldades enfrentadas para implementar a efetiva equidade e revelar as formas de discriminação ainda existentes em desfavor às mulheres.

\section{REFLEXOS DA LUTA PELA IGUALDADE FEMININA NA LEGISLAÇÃO INTERNACIONAL E BRASILEIRA}

A preocupação manifestada pelo movimento e pelos militantes em geral colocou em pauta a discussão das relações de gênero, tomando a mulher como sujeito de direitos e foco de ações públicas e políticas, suscitando negociações nesse sentido em âmbito internacional e doméstico.

Esse processo de legitimação refletiu-se na previsão de instrumentos jurídicos hábeis para a garantia e implementação desses direitos, redefinindo a noção de cidadania feminina. ${ }^{11}$ Destacam-se as cartas e convenções internacionais como a Carta das Nações Unidas de 1945 e a Declaração Universal dos Direitos Humanos de 1948, ambas garantindo a igualdade entre homens e mulheres, mas em especial a Convenção sobre a Eliminação de Todas as Formas de Discriminação contra a Mulher - CEDAW (1979), por ser um instrumento específico de proteção às mulheres.

A CEDAW, juntamente com seu Protocolo Facultativo, incorporados ao direito brasileiro, respectivamente, através dos Decretos no 4.377/2002 e no 4.316/2002, ${ }^{12}$ assimilam na exposição de motivos a

\footnotetext{
${ }^{9}$ ANDREUCCI, A. C. P. T. Igualdade de gênero e ações afirmativas: desafios e perspectivas para as mulheres brasileiras pós Constituição Federal de 1988. São Paulo: LTR, 2012.pg.107.

${ }^{10}$ MIGUEL, L. F.. O Feminismo e a Política. In: MIGUEL, L. F., BIROLI, F.. Feminismo e política: uma introdução. 1aed. São Paulo: Boitempo, 2014.p.27

${ }^{11}$ PRÁ, J. R. Mulheres, direitos políticos, gênero e feminismo. Cad. Pagu, Campinas, no43, 2014. p.175

${ }^{12}$ A CEDAW foi inicialmente incorporada ao direito interno pelo Decreto $\mathrm{n}^{\circ} 89.460$ no ano de 1984, posteriormente revogado pelo Decreto no 4.377/2002, que veio no sentido de excluir as ressalvas antes feitas aos documentos, como pode ser percebido no
} vol.10, nº. 03, Rio de Janeiro, 2017.pp. 1610-1632 
compreensão de que a discriminação viola os princípios da igualdade e da dignidade humana. Registra-se a preocupação, já constante no preâmbulo, sobre o estabelecimento da igualdade de fato e principalmente a percepção dos efeitos que a discriminação causa, como a dificuldade de participação "nas mesmas condições que o homem, na vida política, social, econômica e cultural de seu país", além do obstáculo que isso representa no desenvolvimento de suas potencialidades. Nessa busca por equidade, a possibilidade de adoção de meios como as ações afirmativas encontra respaldo no artigo $4^{\circ}$, item 1 , da referida convenção, verbis:

A adoção pelos Estados-Partes de medidas especiais de caráter temporário destinadas a acelerar a igualdade de fato entre o homem e a mulher não se considerará discriminação na forma definida nesta Convenção, mas de nenhuma maneira implicará, como consequência, a manutenção de normas desiguais ou separadas; essas medidas cessarão quando os objetivos de igualdade de oportunidade e tratamento houverem sido alcançados. ${ }^{13}$

Essas medidas e ações especiais de caráter temporário têm por objetivo tornar mais célere o estabelecimento da igualdade material entre homens e mulheres no pleno exercício de direitos, "[...] assegurando ao segmento feminino igual acesso e oportunidades na vida política e pública, assim como em educação, saúde e emprego, com ênfase na situação das mulheres rurais." ${ }^{14}$

Outro ponto relevante da motivação apresentada é o papel dos pais, cuja responsabilidade compartilham -e não somente da figura feminina - na criação da família, bem como a ausência de reconhecimento adequado da atuação da mulher nesse campo, em oposição à ideia de que este seria um papel exclusivamente feminino.

Por fim, ressaltam-se as Convenções no 100 (1951) - sobre a Igualdade de Remuneração de Homens e Mulheres Trabalhadores por Trabalho de Igual Valor - e no 111 (1958) - sobre a Discriminação em Matéria de Emprego e Ocupação - ambas da Organização Internacional do Trabalho - OIT, vigentes no Brasil em 1958 e 1966 respectivamente ${ }^{15}$. A primeira estabelece o dever de remuneração igual entre os sexos, compreendida a remuneração ordinária e quaisquer verbas pagas direta ou indiretamente ao empregado (a), vedando distinção exclusivamente pelo sexo. A segunda fixa no art.1 ${ }^{\circ}$ - 1, letra a, a proibição de distinção fundada no sexo "que tenha por efeito destruir ou alterar a igualdade de oportunidade ou de tratamento em matéria de emprego ou profissão".

No que concerne à legislação brasileira, a Constituição de 1934 estatuiu determinação inexistente até aquele momento, declarando a isonomia de todos diante da lei, citando expressamente o gênero como um dos critérios vedados de discriminação, além de fixar a identidade de salários para exercício de funções equivalentes. $\mathrm{O}$

art. 1: A Convenção sobre a Eliminação de Todas as Formas de Discriminação contra a Mulher [...] será executada e cumprida tão inteiramente como nela se contém. Disponível em <http://legis.senado.gov.br/legislacao/ListaNormas.action?numero=89460\&tipo_norma=DEC\&data=19840320\&link=s> e <https://www.planalto.gov.br/ccivil_03/decreto/2002/d4377.htm>.Acesso em 11 nov. 2015

${ }^{13}$ CEDAW, art. $4^{\circ}$, item 1 .

${ }^{14}$ PRA, J R. e EPPING, L. Cidadania e feminismo no reconhecimento dos direitos humanos das mulheres. Revista Estudos Feministas, vol.20(1), 2012.p. 39.

15 Convenções 100 e 111 da OIT, disponíveis em: <http://www.oitbrasil.org.br/node/445> e <http://www.oitbrasil.org.br/node/472> 
avanço noticiado neste ponto, entretanto, foi logo suprimido na Constituição de 1937, que fixava somente a igualdade entre todos, da mesma maneira que a Constituição de 1946. A Carta de 1967 "declarou que todos são iguais perante a lei, sem distinção de raça, trabalho, credo religioso e convicções políticas, e ainda estabeleceu que a lei puniria pelo preconceito de raça". ${ }^{16}$

A Constituição Federal de 1988, por sua vez, ao abrir o rol de direitos e garantias fundamentais, no seu art. $5^{\circ}$ prevê a igualdade (genérica) perante à lei e em seguida, no inciso I, estabelece que "homens e mulheres são iguais em direitos e obrigações, nos termos desta Constituição". Outrossim, destaca-se o tratamento constitucional à instituição familiar, com a previsão de igual exercício dos direitos e deveres no seio familiar - art. $226, \$ 5^{\circ}, \mathrm{CF} / 88$-, bem como o dever do Estado em criar "mecanismos para coibir a violência no âmbito de suas relações” - art. 226, $\$ 8^{\circ}$.

Ainda no patamar das normas constitucionais, sinala-se o rol de direitos sociais, em que se pode verificar no art. $7^{\circ}$, inciso XX, a "proteção do mercado de trabalho da mulher, mediante incentivos específicos, nos termos da lei", bem como no inciso XXX, a "'proibição de diferença de salários, de exercício de funções e de critério de admissão por motivo de sexo, idade, cor ou estado civil”. A seu turno, a Consolidação das Leis do Trabalho igualmente trata do tema, estabelecendo no art. $5^{\circ}$ que "a todo o trabalho de igual valor corresponderá salário igual, sem distinção de sexo", o que é reforçado no capítulo II, sobre a remuneração dos trabalhadores, onde o art. 461 prevê que "sendo idêntica a função, a todo trabalho de igual valor, prestado ao mesmo empregador, na mesma localidade, corresponderá igual salário, sem distinção de sexo, nacionalidade ou idade”. $\mathrm{Na}$ atual quadra, foi afastado o princípio da proteção da mulher e o Estado assume o dever de adotar políticas de promover o acesso ao trabalho pela mulher, não havendo espaço, em regra, para as regras proibitivas de cunho "protetor", como a vedação do trabalho noturno, que, no passado, refletia a compreensão do papel da mulher como principal mantenedora do lar. ${ }^{17}$

Contudo a compreensão do dever de promover a plena igualdade entre homem e mulher, presente nas normas internacionais e no próprio ordenamento constitucional brasileiro, não é suficiente para erradicar o preconceito contra a mulher. A cada espaço conquistado pela mulher, novas formas de preconceito passam a ser detectadas, de modo a permitir uma tipificação das formas de discriminação.

\section{FORMAS DE MANIFESTAÇÃO DA DISCRIMINAÇÃO CONTRA AS MULHERES}

Não obstante a caminhada histórica do movimento feminista, dos grupos de mulheres e defensores em geral da igualdade de gênero, somada aos instrumentos legais que formalmente preveem a isonomia de direitos e a

\footnotetext{
${ }^{16}$ ANDREUCCI, A C. P. T. Igualdade de gênero e ações afirmativas: desafios e perspectivas para as mulheres brasileiras pós Constituição Federal de 1988. São Paulo: LTR, 2012.pg. 82-84
} 
implementação de mecanismos jurídicos para obtenção desse patamar de equidade, verificam-se demandas e padrões de exclusão ou preterição baseados em gênero, demonstrando que a desigualdade entre gêneros permanece atuante na sociedade.

Compreender como a discriminação é conceituada pelos textos legais e pela doutrina, bem como a maneira como esta ainda é observada na estrutura social do presente, torna-se essencial para a superação do problema da desigualdade. Especificamente na redação da CEDAW a discriminação contra mulheres é assim definida no artigo $1^{\circ}$ :

Para os fins da presente Convenção, a expressão "discriminação contra a mulher" significará toda a distinção, exclusão ou restrição baseada no sexo e que tenha por objeto ou resultado prejudicar ou anular o reconhecimento, gozo ou exercício pela mulher, independentemente de seu estado civil, com base na igualdade do homem e da mulher, dos direitos humanos e liberdades fundamentais nos campos político, econômico, social, cultural e civil ou em qualquer outro campo.

Para qualificar uma ação como discriminatória não é necessário que o propósito de preconceito ou distinção em desfavor de indivíduo ou grupo seja manifesto, pois basta que se perceba o efeito iníquo da ação ou medida para que sejam consideradas discriminatórias. A discriminação, assim compreendida, pode se apresentar de várias formas no âmbito das relações sociais, sendo comum a doutrina apresentar as categorias de discriminação direta, "[...]quando há tratamento desigual, menos favorável, e endereçado ao indivíduo ou ao grupo, motivado por um critério de diferenciação juridicamente proibido"18 e a indireta, representada pelas "[...]realidades permanentes que se reproduzem e se reforçam ao longo do tempo por meio da manutenção de medidas aparentemente neutras mas efetivamente discriminatórias". ${ }^{19}$

De mesmo modo, o fenômeno da discriminação também é objeto de compreensão sob o ponto de vista institucional, partindo sua perspectiva não da ação individual ou de pequenos grupos específicos, mas sim da maneira como a sociedade se organiza e como as relações sociais ocorrem, criando um padrão de comportamento. ${ }^{20}$ Nesse sentido, o conceito de discriminação institucional é definido por Henry como

aquelas leis, costumes e práticas estabelecidos, que sistematicamente refletem e produzem iniquidades baseadas no grupo em qualquer sociedade. Uma instituição pode ser tendenciosa mesmo que seus indivíduos tenham ou não a intenção de manter essas práticas. ${ }^{21}$ [tradução nossa]

Henry apresenta o exercício de poder com uma das circunstâncias conectadas a essas práticas

\footnotetext{
${ }^{17}$ LOPES, C. M. S. Direito do trabalho da mulher: da proteção à promoção. Cadernos Pagu, ed. 26, 2006. p.426.

${ }^{18}$ RIOS, Roger Raupp. Direito da Antidiscriminação: discriminação direta, indireta e ações afirmativas. Porto Alegre, Livraria do Advogado, 2008.pg. 89

${ }^{19}$ Ibid.,p. 21

${ }^{20}$ Ibid., p. 135

21 "Those established laws, customs, and practices which systematically reflect and produce group-based inequities in any society. An institution may be biased whether or not the individuals maintaining those practices have biased intentions." HENRY, P.J. Institutional Bias, In: DOVIDIO, John F. (Org.), The Sage Handbook of Prejudice, Stereotyping and Discrimination. London: Sage, 2010.p. 427.
} 
assimiladas, afirmando que os grupos que detém o controle das instituições são, usualmente, os mesmos que podem determinar a implementação e retificação de práticas que constroem essa instituição, o que reflete na percepção do que é ou não discriminação institucional. As ideologias legitimadoras são outro aspecto crucial, visto que servem para situar e dar razão ao comportamento discriminatório. Essas ideologias podem ter como origem valores religiosos, morais, questões biológicas, entre outros, podendo exemplificar uma dessas ideologias como o estereótipo. ${ }^{22}$

Em seu estudo sobre "Preconceito, Estereótipos e Discriminação", Henry procura estruturar as modalidades de discriminação verificadas nas relações sociais, indicando quatro abordagens, partindo da observação da intenção do agente discriminador - se suas condutas são explícitas, intencionais e não intencionais, ou implícitas - e de sua origem, i.e., se essas condutas provem de um padrão de práticas da instituição ou da soma das ações dos agentes que a compõem. Ressalta-se que, embora usualmente o termo "discriminação institucional" esteja vinculado ao padrão de comportamento exercido por um grupo em desfavor de outro, não se pode excluir a soma das ações individuais (intencionais ou não) do conceito, uma vez que o foco da discriminação institucional é o resultado dessas ações que refletem iniquidades baseadas em características de certo grupo (origem étnica, gênero, orientação sexual). ${ }^{23}$

Verifica-se, assim, que não só os elementos trazidos dialogam com as formulações dos militantes pela equidade de gênero, como também podem, até mesmo devem compor a análise para solução das desigualdades, uma vez que representam barreiras à ascensão social, política e econômica feminina em pé de igualdade aos homens. Daí a necessidade de

[... ] examinar a dinâmica da cultura institucional, a reprodução de relações de iniquidade, a dimensão estrutural da exclusão e discriminação, a resistência institucional ao desafiar o status quo, e a hegemonia das normas implícitas dominantes..$^{24}$ [tradução nossa]

Um exemplo dessas barreiras pode ser colhido da experiência norte-americana. Um relatório da Glass Ceiling Comission, do ano de 1995, apontou três barreiras artificiais enfrentadas por mulheres e "pessoas de cor": sociais, governamentais e de estrutura interna. No estudo, conduzido por O’Melveny, as barreiras sociais são compreendidas como aquelas que incluem os preconceitos e estereótipos, tanto conscientes quanto inconscientes. Já as barreiras governamentais referem à ausência de controle e execução das leis de modo consistente; e, por fim, as barreiras nas estruturas internas, referem o modo que as minorias são tratadas no âmbito do trabalho, inclusive quanto ao recrutamento, em que não se busca inclúi-las, indicando a ausência de

\footnotetext{
${ }^{22}$ Ibid.p. 430-433

${ }^{23}$ HENRY, P.J. Institutional Bias, In: DOVIDIO, John F. (Org.), The Sage Handbook of Prejudice, Stereotyping and Discrimination. London: Sage, 2010.p. 434-435

${ }^{24}[\ldots]$ examine the dynamics of institutional culture, the reproduction of relationships of inequality, the structural dimensions of exclusion and discrimination, institutional resistance to challenges to the status quo, and the hegemony of unstated dominant norms. SHEPPARD, C. Equality Rights and Institutional Change: Insights from Canada and the United States. Arizona Journal of
} vol.10, nº. 03, Rio de Janeiro, 2017.pp. 1610-1632 
treinamento e possibilidade de desenvolvimento. Cita-se como exemplo, neste ponto, o uso de padrões tendenciosos na análise do desempenho no ambiente laboral. ${ }^{25}$

Cabe ressaltar, ainda, a existência de um conceito de discriminação que atenta a essa multiplicidade de elementos e que deve sua elaboração ao movimento feminista norte americano. Esse movimento questionou o essencialismo de uma identidade única feminina, apontando a necessidade de se trazer à luz outros elementos. Passa-se a discutir, então, a discriminação interseccional, também chamada de discriminação múltipla, que denuncia a natureza da experiência discriminatória quando existente a intersecção de vários critérios proibidos (raça, classe, etc.), ao entender a intersecção como geradora de um resultado específico em razão da combinação destes aspectos. Esses aspectos, por interagirem entre si de maneira distinta em cada sociedade e momento histórico, devem ser analisados com atenção, pois não significam apenas um somatório de características fixas alheias entre si. ${ }^{26}$

Diante da complexidade deste fenômeno, assimilar os diversos "modus operandi" da discriminação na sociedade torna-se fundamental na busca por métodos a serem utilizados na sua superação. No caso da discriminação institucional, o desafio reside em perceber este comportamento na relação entre os padrões de comportamento e ações dos indivíduos, frente à intencionalidade. Como sugere Henry, é imprescindível atentar para a singularidade de cada modo para se chegar a soluções eficazes. Quanto à discriminação representada pela soma das ações dos indivíduos, percebe-se mais fácil combater o comportamento discriminatório quando presente a não-intencionalidade, sendo possível a redução ou eliminação deste tipo de ação através de programas educacionais, de conscientização do preconceito, até mesmo empregando minorias em posições decisórias. De outro modo, se presente a intencionalidade, depara-se com a dificuldade de utilizar a conscientização como ferramenta, pois, muitas vezes, os indivíduos que detém o poder não têm interesse efetivo em alterar esse status para favorecer minorias ou grupos. Sendo este o caso, por vezes há a necessidade da atuação de mecanismos legais, como repressões formais de superiores ou o ajuizamento de ação motivada pela discriminação sofrida. ${ }^{27}$

Para o enfrentamento da discriminação oriunda dos padrões comportamentais da instituição, não é possível focar a atenção apenas no nível individual, pois deve-se atentar também para a diferença na intencionalidade. Legislação de direitos civis e garantias legais, bem como manifestações e protestos populares que envolvam esses grupos preteridos, podem ser úteis no combate dos padrões de práticas institucionais quando há intenção de discriminar. Outrossim, deparando-se com práticas não intencionais nesse ponto, pode-se lançar

International and Comparative Law, v.15,1998.pg. 147

${ }^{25}$ O'MELVENY, M. K. Playing the "Gender" Card: affirmative action and working women. Kentucky Law Journal, vol. 84,19951996.p. 892

${ }^{26}$ RIOS, R. R. e SILVA, R. Discriminação múltipla e discriminação interseccional: aportes do feminismo negro e do direito da antidiscriminação. Rev. Bras. Ciênc. Polít. n.16,2015 p.11-37. 
mão de "políticas como ações afirmativas, políticas de bem-estar social, programas de recrutamento de minorias, bem como por meio do envolvimento de minorias nas decisões sobre políticas e procedimentos". ${ }^{28}$ Alguns desses mecanismos se mostram presentes nos projetos normativos que logo iremos analisar.

\section{CENÁRIO ATUAL DA DESIGUALDADE CONTRA A MULHER E MEDIDAS DE COMBATE}

O contexto histórico, as demandas sociais por equidade, os instrumentos legais e estudos já descritos servem como pano de fundo para a reflexão a respeito da situação brasileira. Nas últimas décadas, ampliou-se a participação econômica e política das mulheres brasileiras, que já são melhor remuneradas, ocupam atividades cuja presença histórica se dava substancialmente por homens, bem como acessam posições de gestão, administração e, no âmbito político, estão em maior representatividade do que em períodos anteriores lembrando que nesta última década uma mulher elegeu-se Presidente da República por duas vezes consecutivas. Em retrospecto, duas fases marcam essa inserção progressiva das mulheres na ampliação de seus espaços tradicionais:

a. Primeiro passo: da casa ao mercado de trabalho

A evolução dos dados censitários demonstra uma ampliação inicial dos espaços ocupados pelas mulheres no mercado de trabalho, ${ }^{29}$ indicando que essa autonomia foi impulsionada pela melhoria na educação e pelo aumento na quantidade de anos de estudo das mulheres, o que não significa inferir que a discriminação de gênero seja algo superado. ${ }^{30}$

\footnotetext{
${ }^{27}$ HENRY, P.J. Institutional Bias, In: DOVIDIO, John F. (Org.), The Sage Handbook of Prejudice, Stereotyping and Discrimination. London: Sage, 2010. p. 436. Tradução nossa.

${ }^{28}[\ldots]$ policies such as affirmative action, welfare policies, minority recruitment programs, as well as through involvement of minority input in decisions about policies and procedures. HENRY, P.J. Institucional Bias, In: DOVIDIO, John F. (Org.), The Sage Handbook of Prejudice, Stereotyping and Discrimination. Londres: Sage, 2010. p. 437

${ }^{29}$ Pesquisa realizada junto ao IPEA revela que nos Estado Unidos, "as mulheres passaram de $18 \%$ da População Economicamente Ativa (PEA) em 1900 para 32\% em 1960 e 46\% em 1992. Foi uma mudança vista em todo o mundo ocidental e o Brasil não escapou aos seus efeitos — no Brasil as mulheres foram de 32\% da PEA em 1977 para 46\% em 2001, fechando em 24 anos o hiato que as mulheres americanas fecharam em 32". SOARES, Sergei; IZAKI, Rejane. A Participação Feminina no Mercado de Trabalho. Rio de Janeiro, 2002. Disponível em: http://www.ipea.gov.br/portal/images/stories/PDFs/TDs/td_0923.pdf

${ }^{30}$ Embora as mulheres sejam maioria na população de 10 anos ou mais de idade, elas são minoria na população ocupada, mas estão em maioria entre os desocupados. Alguns dados corroboram a situação desfavorável da mulher no mercado de trabalho: por exemplo, "aproximadamente 35,5\% das mulheres estavam inseridas no mercado de trabalho como empregadas com carteira de trabalho assinada, percentual inferior ao observado na distribuição masculina (43,9\%). As mulheres empregadas sem carteira e trabalhando por conta própria correspondiam a 30,9\%. Entre os homens este percentual era de $40 \%$. O percentual de mulheres inseridas como empregadores era de 3,6\% enquanto na distribuição masculina era 7,0\%"; além disso, "o rendimento de trabalho das mulheres, estimado em R \$ 1.097,93, continua sendo inferior ao dos homens (R \$ 1.518,31). Em 2009, comparando a média anual dos rendimentos dos homens e das mulheres, verificou-se que, em média, as mulheres ganham em torno de $72,3 \%$ do rendimento recebido pelos homens. Em 2003, esse percentual era 70,8\%” IBGE. Pesquisa Mensal de Emprego (PME) - Mulher no Mercado de Trabalho: perguntas e respostas, 2010. Disponível em vol.10, nº. 03, Rio de Janeiro, 2017.pp. 1610-1632 1620
} 
Com efeito, os desafios permanecem em pontos centrais como equidade na remuneração por exercício de mesma atividade, acesso a cargos superiores, representação e participação política eficaz, bem como divisão proporcional dos afazeres domésticos, além das "duplas" jornadas que se busca cumprir, ou seja, a mulher ainda necessita conciliar estes afazeres com as questões profissionais e os cuidados com a família. O próprio aumento na participação política enfrenta dificuldades oriundas da construção social acerca dos papéis de cada sexo, compreendendo-se, muitas vezes, a arena política como âmbito naturalmente masculino. ${ }^{31}$

Inicialmente, ressaltam-se os dados acerca da distribuição ocupacional por raça e gênero no Brasil entre as décadas de 1960 e 1980 no mercado urbano, nos quais é possível perceber, como aponta Lovell, que houve um aumento da representação feminina nos empregos qualificados, em especial em escritórios, atividades referidas como "colarinho branco" (gerentes administrativos, profissionais técnicos e de escritório ou administradores). No acesso a educação também foi observada melhora da inclusão feminina. Cumpre ressaltar que, embora tenha havido melhora no status socioeconômico das mulheres em geral, há a necessidade de observar as estatísticas também pelo recorte de raça, uma vez que apontam diferenças significativas entre mulheres brancas e negras. ${ }^{32}$

Em 1960, ponto de partida da análise estatística realizada por Lovell, a ocupação feminina se dava substancialmente nas atividades manuais não qualificadas, bem como prestação de serviços pessoais, chamados "colarinho azul". Em relação a distinção do percentual da participação dessas mulheres conforme a sua raça, os dados demonstram que, na década de 1960 "uma porcentagem avassaladora de 88\% das afro-brasileiras empregadas se enquadravam nessas subcategorias, em contraste com os 52\% das mulheres brancas"33. Já em 1980, "63\% das mulheres brancas estavam trabalhando nos empregos de maior prestígio e maior remuneração, em comparação com os $34 \%$ das afro-brasileiras." 34

Nas atividades englobadas na categoria colarinho azul no ano de 1980, embora tenha ocorrido diminuição de representantes femininas, percebe-se, ainda, disparidade em razão da raça, sendo 66\% mulheres afro-brasileiras e $37 \%$ mulheres brancas. ${ }^{35}$ Tal mudança, afirma a autora, deu-se em virtude dos ganhos educacionais, obtidos tanto pelas mulheres como quanto os afro-brasileiros em geral, bem como diante do aumento no número de empregos ocorrido nas décadas de 1960 até 1980, acompanhando o aumento da urbanização do país. Não obstante o avanço social alcançado, observa-se que a ocupação de certos cargos e posições de poder permanece destinada a um segmento específico da população:

\footnotetext{
http://www.ibge.gov.br/home/estatistica/indicadores/trabalhoerendimento/pme_nova/Mulher_Mercado_Trabalho_Perg_ Resp.pdf

${ }^{31}$ MIGUEL, Luis Felipe. Gênero e representação política. In: MIGUEL, Luis Felipe, BIROLI, Flávia. Feminismo e política: uma introdução. 1ªed. São Paulo: Boitempo, 2014.pg. 94.

${ }^{32}$ LOVELL, Peggy A. Raça e gênero no Brasil. Lua Nova, n.35, 1995. p. 39-71.

${ }^{33}$ Ibid.s.pg. 52

${ }^{34}$ LOVELL, Peggy A. Raça e gênero no Brasil. Lua Nova, n.35, 1995. p. 39-71.

${ }^{35}$ LOVELL, loc. cit.
} 
[... mesmo com a melhoria dos níveis educacionais, evidências de segregação persistente em virtude do sexo e raça no mercado de trabalho podem ser notadas ( ... ). Em resumo, os cargos mais importantes de gerência e administração permanecem sendo de domínio dos homens brancos. ${ }^{36}$

No decorrer da interpretação dos dados colhidos pelo estudo, a autora tece conclusão relevante à compreensão do problema de desigualdade social enfrentado tanto por mulheres quanto pela comunidade negra, afirmando existência de discriminação salarial em função do gênero e raça:

As descobertas mais importantes feitas pelas análises de regressão salarial foram que, mesmo depois de controlar e isolar as diferenças de variáveis como experiência profissional, a educação, a ocupação e outros indicadores salariais, as mulheres recebiam menos do que os homens e os afro-brasileiros menos que os brancos. $O$ fato de que a raça e o sexo continuam afetando o valor dos salários de forma substancial mesmo depois de introduzidas essas variáveis indica que a disparidade de renda que existe entre homens e mulheres, brancos e afro-brasileiros, não pode ser reduzida a meras diferenças de posição socioeconômica. Esses resultados sugerem claramente que, no mercado de trabalho urbano brasileiro, as mulheres e afro-brasileiros sofrem discriminação salarial..$^{37}$ [grifo nosso]

Especialmente no que tange às mulheres, poder-se-ia suscitar a hipótese de que eventual discrepância entre a sua remuneração e a masculina teria como motivo os gastos do empregador na compensação em relação às proteções especiais concedidas pelo direito do trabalho - especificamente quanto à maternidade e o afastamento da funcionária decorrente destas previsões. Por oportuno, ressalta-se que o salário-maternidade é benefício de natureza previdenciária, sendo previsto no art. 18, da Lei 8.213/1991 e suportado diretamente pela Previdência Social em favor à segurada. ${ }^{38} \mathrm{O}$ argumento no sentido de que o sobre-custo é um encargo severo ao empregador é comum na defesa de salários mais baixos às mulheres, perpetuando sua discriminação e restrição de oportunidades.

Uma pesquisa da OIT, porém, ao estudar tal hipótese nos países da América Latina na década de 1990, elaborou conclusões relevantes em sentido contrário ao senso comum. Como estudado por Andreucci, “[...] os custos monetários para o empregador em relação à contratação das mulheres são muito reduzidos. Eles representam menos de $2 \%$ da remuneração bruta mensal das mulheres”, e sugerem que

[...] quando se fala nos "custos" das mulheres associados à maternidade, a impressão que fica é que as mulheres trabalhadoras teriam um número de filhos muito maior do que o que aparece nos dados ( ... ) ou que o "risco" da maternidade seria algo quase permanente. ${ }^{39}$

Persiste na área profissional, então, a discriminação, ainda que de modo não tão explícito, mas com reflexos significativos em termos de remuneração, o que influencia o ritmo da diminuição dessas iniquidades. Cruz

\footnotetext{
${ }^{36}$ Ibid., p.53.

${ }^{37}$ Ibid., p. 63.

${ }^{38}$ Nos termos da Lei 8.213/1991: art. 71. O salário-maternidade é devido à segurada da Previdência Social, durante 120 (cento e vinte) dias, com início no período entre 28 (vinte e oito) dias antes do parto e a data de ocorrência deste, observadas as situações e condições previstas na legislação no que concerne à proteção à maternidade; e art. 71-A, $\$ 1^{\circ}$ : $\mathrm{O}$ salário-maternidade de que trata este artigo será pago diretamente pela Previdência Social

${ }^{39}$ ANDREUCCI, A. C. P. T. Igualdade de Gênero e ações afirmativas: desafios e perspectivas para as mulheres brasileiras pós Constituição Federal de 1988. São Paulo: LTr, 2012.p. 118.
} 
aponta, inclusive, como fruto do "sexismo inconsciente" a razão pela distinção no salário feminino para mesma função. O autor refere que na pesquisa intitulada Retrato das Desigualdades de Gênero e Raça realizada no período compreendido entre 1996 e 2007, o Instituto de Pesquisa Econômica Aplicada (IPEA) concluiu que "caso não haja uma aceleração/aprofundamento de políticas públicas de igualdade de gênero, serão precisos nada menos do que 87 anos para igualar os salários entre homens e mulheres no Brasil”. ${ }^{40}$

A discussão sobre a relação entre a esfera pública e a esfera privada foi questão levantada também pela crítica feminista, inclusive pela significativa repercussão no âmbito do trabalho, especialmente em função da ideia de preservação da privacidade da esfera privada. Defendia-se que, em razão da esfera privada ser o âmbito da individualidade e da construção das relações de afeto, em oposição à esfera pública em que se abrigariam as relações pautadas pela impessoalidade, não caberiam, ipso facto, intervenções estatais. Essa preservação da privacidade e da entidade familiar tende a proteger menos os indivíduos em posição hierarquicamente inferior, servindo como manutenção da dominação masculina. Dessa maneira, ao almejar-se relações mais justas entre gêneros deve-se assimilar as características das relações de cada indivíduo nas instituições de que participa, dentre elas a familiar, e o modo como essas instituições o atingem. ${ }^{41}$

Faz sentido, assim, abandonar a visão de que a esfera pública e a esfera privada correspondem a "lugares" e "tempos" distintos na vida dos indivíduos, passando a discuti-las como um complexo diferenciado de relações, de práticas e de direitos - inclú́dos os direitos à publicidade e à privacidade - permanentemente imbricados, uma vez que os efeitos dos arranjos, das relações de poder e dos direitos garantidos em uma das esferas serão sentidos na outra. ${ }^{42}$

Além disso, os estereótipos de gênero, que atribuem à mulher uma domesticidade, afetuosidade, e melhor qualificação para o cuidado do lar e da família -o que, alega-se, seria intrínseco à sua natureza, em oposição ao papel atribuído ao homem-, reforçam uma preconcepção prejudicial às mulheres, revelando um espaço de manutenção da hierarquia e dominação masculinas. Embora o exercício da maternidade tenha sofrido, na sociedade moderna, uma diferenciação oriunda da melhoria nos métodos contraceptivos -proporcionando o planejamento familiar e, com isso, certa independência feminina no planejamento profissional e legitimação do seu status de cidadã $-{ }^{43}$, a hierarquização ainda é presente.

Discussões sobre a dinâmica familiar evidenciaram a necessidade de relativizar essa privacidade e atentarse ao fato de que, diante dessa relação de poder e hierarquização, a mulher sofria restrições à liberdade e autonomia na esfera privada. Por exemplo, embora a mulher contribua financeiramente no lar, a administração

\footnotetext{
${ }^{40}$ CRUZ, A. R. de S. O Direito à Diferença. Belo Horizonte: Arraes. 2009.pg. 46-47

${ }^{41}$ BIROLI, F. O publico e o privado. In: MIGUEL, L. F., BIROLI, F. Feminismo e política: uma introdução. 1aed. São Paulo: Boitempo, 2014. p. 31-34

${ }^{42}$ BIROLI, F. O publico e o privado. In: MIGUEL, L. F., BIROLI, F. Feminismo e política: uma introdução. 1aed. São Paulo: Boitempo, 2014. p.,p.33.

${ }^{43}$ ANDREUCCI, A. C. P. T. Igualdade de Gênero e ações afirmativas: desafios e perspectivas para as mulheres brasileiras pós Constituição Federal de 1988. São Paulo: LTr, 2012.p. 106
} 
dos recursos materiais ainda é vista, no casamento tradicional, como papel do homem; outra manifestação dessa questão de poder (gênero) está vinculada à violência doméstica - haja vista a Lei Maria da Penha (Lei no 11.340, de 2006), editada no intuito de prevenir e combater a violência no âmbito das relações familiares. ${ }^{44}$

Nesse sentido, a inserção da mulher no mercado de trabalho não significou a restruturação da dinâmica familiar, pois as atividades domésticas persistem em sua maioria como encargo para a mulher, percebendo-se uma distribuição desigual nessas atividades. Essa atribuição desproporcional de papéis na família, originada na hierarquização masculina, reflete na ideia culturalmente aceita de que esta, de fato, é a função primordial da mulher, o que reflete não só na justificação de salários inferiores às mulheres (eis que, no senso comum, não são as provedoras financeiras principais da família), como na preferência pelo empregado masculino, diante da sua maior dedicação ao trabalho e "menor" possibilidade de afastamento em razão de eventual necessidade de dedicação presencial aos filhos. ${ }^{45}$

O Relatório Anual Socioeconômico da Mulher de 2014 (RASEAM) corrobora esta situação, indicando que essa divisão por gênero do trabalho em casa prejudica "seu acesso e permanência no mercado de trabalho, bem como a sua ascensão profissional" ${ }^{\prime 6}$ e aponta que, no ano de 2012,

o tempo dedicado ao trabalho principal (mais de 35 horas semanais) e os afazeres domésticos (quase 21 horas semanais), era sempre superior à jornada total dos homens (quase 42 horas dedicadas ao trabalho principal e 10 horas aos afazeres domésticos $[\ldots] .^{47}$

A estrutura demográfica da população do referido ano, fornecida pelo IBGE era composta por $51 \%$ de mulheres, sendo que $52 \%$ destas se autodeclararam negras. ${ }^{48}$ Essa autonomia feminina que se busca desenvolver, passa indispensavelmente pela autonomia econômica em pé de igualdade com os homens, especialmente considerando-se que 38\% dos domicílios possuíam uma mulher como pessoa de referência provedora. ${ }^{49}$ Nesse estudo, a taxa de atividade, ou seja, o percentual das mulheres empregadas, permanecia inferior à masculina: 64,2\% das brasileiras exerciam atividade remunerada ao passo que $86,2 \%$ dos homens ocupam a mesma posição. ${ }^{50}$

Aproveitando ainda os dados do relatório RASEAM, relaciona-se o acesso à creche como um fator muito importante na taxa de ocupação das mulheres, pois "entre as mulheres com todas/os as/os filhos/os de 0 a 3 anos na creche, $72,9 \%$ estavam ocupadas, enquanto somente $42,6 \%$ daquelas sem nenhum/a filha/o na creche

\footnotetext{
${ }^{44}$ BIROLI, F. O publico e o privado In: MIGUEL, L. F., BIROLI, F. Feminismo e política: uma introdução. 1aed. São Paulo: Boitempo, 2014.p. 39-43

${ }^{45}$ LOPES, C. M. S. Direito do trabalho da mulher: da proteção à promoção. Cadernos Pagu, ed. 26, 2006. p. 428

${ }^{46}$ BRASIL. Presidência da República Secretaria de Políticas para as Mulheres. Relatório Anual socioeconômico da Mulher (RASEAM). 1a Impressão. 2015 p.16. O presente relatório é de organização da Secretaria de Políticas para as Mulheres da Presidência da República, com dados do ano de 2012, cujo objetivo é fornecer subsídios à formulação e implementação de políticas públicas.

${ }^{47}$ BRASIL. Presidência da República Secretaria de Políticas para as Mulheres. Relatório Anual socioeconômico da Mulher (RASEAM). 1a Impressão. 2015 p, p. 20.

${ }^{48}$ Ibid., p. 11.

${ }^{49}$ Ibid., p. 13

${ }^{50}$ Ibid., p. 16
} 
tinham ocupação[....]". A defasagem de uma estrutura de apoio como as creches, aliada à sobrecarga feminina com o cuidado familiar, geram, como revelam os dados estatísticos, um percentual menor de mulheres ocupadas quando se verifica a precariedade da rede de apoio, contribuindo negativamente para sua autonomia financeira. ${ }^{51}$ Esse quadro sugere que, além de medidas compensatórias afirmativas, outras ações são necessárias para plena equiparação no exercício de direitos, envolvendo políticas públicas com foco no planejamento familiar e na estrutura de apoio à maternidade, como o investimento em creches e programas escolares de proteção à infância.

b. Segundo passo: da casa e do mercado ao espaço político

A eficaz participação política das mulheres também integra a análise da equidade material feminina. Ao estudar o contexto da América Latina, em termos de participação e envolvimento das mulheres ocupando cargos ministeriais, Blanco teceu algumas ponderações sobre os projetos desenvolvidos pelo Banco Interamericano de Desenvolvimento (BID) durante os anos de 2002 e 2007. O estudo indica que o aumento dos cargos ministeriais nos quais havia uma mulher não correspondeu, necessariamente, a um aumento de poder ou melhoria no desenvolvimento, sugerindo que um resultado distinto é possível somente com uma mudança estrutural política e administrativa, em razão da dinâmica de funcionamento das decisões políticas. ${ }^{52}$

Isso porque, demonstra a autora, foi percebido pela maior parte das ministras que o fato de disporem formalmente de uma parcela poder não significava o seu exercício fático. Em geral, a dificuldade em implementar políticas públicas residia na não-inclusão das ministras nos espaços decisórios mais restritos e informais, sendo nesses momentos que se alinhavam as políticas posteriormente formalizadas, havendo pouco espaço de negociação e exercício de suas prerrogativas. Essa é umas das principais questões levantadas, uma vez que as mulheres nessas posições enfrentam

[... ] a limitação de não ter poder suficiente e as ferramentas necessárias para alcançar a transformação do modelo de desenvolvimento voltado às políticas públicas visando a promoção do bem comum. A incapacidade de incluir questões sobre mulheres na agenda do desenvolvimento também preocupou muitas das mulheres. Em outras palavras, falta-lhes poder real para perseguir políticas estatais que vão além da política oficial da administração ${ }^{53}$. [Tradução nossa]

Sobre os relatos e experiências das mulheres incluídas nos projetos do BID, Blanco registra que, embora as ministras afirmassem não terem enfrentado discriminação para alcançar e exercer o cargo, elas lidam com um pesado desafio nos seguintes sentidos:

a necessidade de repetidamente provar que elas são mais capazes do que os homens em posição similar; (b) a necessidade de equilibrar sua vida pessoal com as responsabilidades

\footnotetext{
${ }^{51}$ Ibid., p. 17.

${ }^{52}$ BLANCO, Eglé Íturbe de. Women: Power and Development in Latin America. University of St. Thomas. Vol .5:3, 2008.pg. 690

53 Ibid. p. 690-691 [...] the limitation of not having enough power or the necessary tools to achieve a transformation of the development model towards policies aimed at fostering the common good. Their inability to add women's issues to the development agenda also concerned many women. In other words, they lacked actual power to pursue state policies that would go beyond the administration's official policy.
} 
públicas; e (c) a necessidade de ganhar respeito - para ser considerada como pares dos ministros homens no processo de decisão colegiada. ${ }^{54}$ [tradução nossa]

Nota-se que o comportamento indicado reflete o chamado "capital social", entendido como "a extensão e eficácia da rede social e capacidade organizacional de uma comunidade, a qual permite que seus membros efetivamente alcancem objetivos e conquistem recursos em uma variedade de domínios" 55 , que é desigual entre os grupos sociais, relacionando-se ao conceito de discriminação institucional já visto. Aqueles grupos que detêm o poder na instituição - no grupo específico desta análise, os homens - perpetuam a orientação dos benefícios aos seus interesses, estabelecendo uma barreira em função do gênero, deixando à margem os demais - no caso, as mulheres.

Essa permanência na presunção de que mulheres não estão aptas e qualificadas o suficiente para tais funções, acarreta, como indicado, uma necessidade contínua das mulheres "provarem-se" nesse sentido, o que contudo não é infligido aos colegas homens nos gabinetes governamentais. ${ }^{56}$ Disso é possível depreender que mesmo no contexto político recente - os dados referem ao período de 2002 até 2007 - há barreiras que vão além da existência e aumento do número de mulheres nos cargos políticos. Isso porque

[...]construído historicamente como um ambiente masculino, o campo político trabalha contra as mulheres (bem como os integrantes de outros grupos em posição de subalternidade), impondo a elas maiores obstáculos para que cheguem às posições de maior prestígio e influência[... $]^{57}$

O dado quantitativo é devastador quando se observa a taxa de a ocupação feminina nos parlamentos mundiais. Em seu estudo sobre o tema, Miguel indica que dos 187 países sobre os quais se obteve dados em julho de 2013 “[...] ]as mulheres ocupam, em média, 21,3\% das cadeiras nos parlamentos nacionais.” E revela, ainda, que "o Brasil, com menos de 9\% de mulheres na Câmara dos Deputados, está entre os piores colocados no ranking internacional, atrás de 154 países." 58

Observa-se, portanto, que a conquista dos direitos e dos espaços públicos se deu paulatinamente, ainda existindo uma presença maior de mulheres no mercado de trabalho em comparação com a esfera política. Contudo a discriminação, oriunda do preconceito e do movimento pela manutenção dos privilégios masculinos,

\footnotetext{
${ }^{54}$ Ibid. p. 688 [... ] (a) the repeated need to prove that they were more capable than men in similar positions; (b) the need to balance their personal lives with their public responsibilities; and (c) the need to earn respect - to be considered on par with the male ministers in collective decision-making.

55 [tradução nossa] HENRY, P.J. Institucional Bias, In: DOVIDIO, John F. (Org.), The Sage Handbook of Prejudice, Stereotyping and Discrimination. Londres: Sage, 2010.p. 433[...] the breadth and effectiveness of a community's social networks and organizational capacity, which can allow members of that community to efficiently accomplish goals and gain resources in a variety of domains.

${ }^{56}$ BLANCO, E. Í. de. Women: Power and Development in Latin America. University of St. Thomas. Vol .5:3, 2008. p. 688

${ }^{57}$ MIGUEL, L. F. Gênero e representação política. In: MIGUEL, L. F., BIROLI, F. Feminismo e política: uma introdução. 1ed. São Paulo: Boitempo, 2014.p.105.

${ }^{58}$ MIGUEL, L. F. Gênero e representação política. In: Miguel, L. F. e BIROLI, F. Feminismo e Política: uma introdução. 1. ed. São Paulo: Boitempo, 2014. p. 93-94. O autor refere ainda, que "desde que o acompanhamento começou a ser feito em 1997 [pela Inter-Parlamentary Union], há uma tendência de ampliação da presença feminina nos parlamentos do mundo, mas em velocidade
} vol.10, nº. 03, Rio de Janeiro, 2017.pp. 1610-1632 
persiste em todos esses meios, em desfavor da inserção e ascensão profissional das mulheres. Se esta é a realidade que se apresenta diante do objetivo de construção de uma sociedade pautada na equidade, tem-se o contexto que legitima o uso de ferramentas que combatam os comportamentos discriminatórios, tal como o Estado brasileiro tenta implementar por meio de determinadas ações afirmativas que asseguram cotas às mulheres no ambiente de trabalho e no espaço político - sobre as quais refletiremos nas considerações finais.

\section{CONSIDERAÇÕES FINAIS}

O objetivo deste trabalho era analisar o contexto de discriminação feminina nos diferentes espaços ocupados por mulheres, tendo em vista a necessidade de compreensão das justificativas que legitimam a adoção de políticas afirmativas com base no gênero.

De um lado, temos os direitos garantidos em diplomas como a Convenção sobre a Eliminação de Todas as Formas de Discriminação contra a Mulher e na própria Constituição Federal do Brasil, que por meio dos princípios da igualdade, na sua dimensão material, e da dignidade da pessoa humana, aliados à ideia de justiça social e sociedade igualitária, balizam a persecução dos objetivos fundamentais da República (sociedade justa, solidária e livre de desigualdades sociais - art. 30).

De outro lado, apontamos fatores que demonstram a permanência das mulheres em posição subalterna, como vítimas de violência e discriminação, nos múltiplos ambientes em que transitam. Vimos que há uma espécie de normalidade garantida ao status mais privilegiado masculino e algumas manifestações dessa dominação têm por objetivo e/ou efeito subjugar, ainda que de modo não-intencional, as mulheres a ambientes restritos em termos de autonomia, bem como valorizar seu trabalho de maneira distinta em relação aos pares masculinos. Observou-se que persiste a divisão desigual dos afazeres domésticos, menor remuneração, inacessibilidade a certos cargos, tudo reflexo de uma estrutura social voltada à manutenção da preferência masculina.

Essa realidade impõe que se discutam as formas de promover transformações nessa estrutura iníqua, a fim de implementar a melhoria do posicionamento feminino no cenário político e empresarial (público e privado), reconhecendo-se tanto um dever de atuação do Estado na aceleração da igualdade material entre homens e mulheres, como, conjuntamente, a demanda dos movimentos sociais para que essa discriminação, originada na dominação masculina, seja esclarecida e combatida.

Como visto, a doutrina propõe métodos de combate à discriminação específicos para cada face do fenômeno (direta, indireta, institucional, interseccional), considerada a natureza de cada uma dessas formas e como elas reproduzem a dominação masculina no momento da adoção de certa medida administrativa ou legal. Observou-se que não só a discriminação direta, mas também a discriminação indireta e institucional, presente em reduzida, com um aumento médio de meio ponto percentual por ano.” p.94. 
hábitos procedimentais e culturas arraigadas, atingem as mulheres. Por serem expressões mais complexas e menos visíveis do fenômeno, está-se diante de hipóteses em que as ações afirmativas, políticas de bem-estar social e inclusão de minorias nos espaços de decisão, se mostram um caminho possível, adequado e necessário para o combate à discriminação.

Ao lado dessas medidas estão as ações afirmativas, originadas com o movimento de direitos civis norteamericano e replicadas em diversos países ao redor do mundo, como Inglaterra, Índia, Austrália, entre outros. ${ }^{59} \mathrm{O}$ enfrentamento da desigualdade feminina oriunda da discriminação de gênero na organização social foi alvo de análise e discussão nos Estados Unidos e também na Comunidade Europeia, especialmente sob o ponto de vista da participação política das mulheres e do acesso a cargos de trabalho. No contexto comunitário, as recomendações, diretivas e programas foram propulsoras no tratamento da questão, sendo direcionadas a todos os Estados-Membros. Esse conjunto de normas, como as Diretivas 75/117/CEE e a 96/694/CE60, tinham o propósito de, em síntese, alcançar o equilíbrio nos processos decisórios, através da participação equânime de homens e mulheres; igualdade de oportunidades; bem como a conciliação entre as esferas privadas e públicas de mulheres e homens. ${ }^{61}$

As convenções internacionais também irradiaram seus efeitos no Brasil, onde atualmente vige a Lei no 9.504/1997 que estabelece, em seu art. 10, $\$ 3^{\circ}$, a meta de participação de 30\% de mulheres nas listas partidárias ${ }^{62}$. Esse percentual foi aumentado em comparação com legislação anterior, Lei 9.100/1995, que fixava a reserva no patamar de 20\%. ${ }^{63}$ Tal medida atende aos deveres dos Estados-Partes da CEDAW, a qual estabelece em seu art. $7^{\circ}$ que

os Estados-Partes tomarão todas as medidas apropriadas para eliminar a discriminação contra a mulher na vida política e pública do país e, em particular, garantirão, em igualdade de condições com os homens, o direito a: a) Votar em todas as eleições e referenda públicos e ser elegivel para todos os órgãos cujos membros sejam objeto de eleições públicas; b) Participar na formulação de políticas governamentais e na execução destas, e ocupar cargos públicos e exercer todas as funções públicas em todos os planos governamentais; c) Participar em organizações e associações não-governamentais que se ocupem da vida pública e política do país. ${ }^{64}$

A inclusão desse grupo minoritário por meio das cotas justifica-se por ir além da mera representação descritiva da sociedade, reproduzindo-a no Parlamento. Se, por um lado, isso não garante, necessariamente, o atendimento das demandas sociais dos eleitores, por outro lado significa a existência de uma política pública para

\footnotetext{
${ }^{59}$ SOWELL, T. Ação afirmativa ao redor do mundo: um estudo empírico. Rio de Janeiro: UniverCidade, 2004. p. 02.

${ }^{60}$ Disponível em http://eur-lex.europa.eu/legal-content/PT/TXT/HTML/?uri=CELEX:31975L0117\&from=PT

e <ttp://eur-lex.europa.eu/legal-content/PT/TXT/HTML/?uri=CELEX:31996H0694\&from=PT>.

${ }^{61}$ BELLINTANI, L. P. Ação Afirmativa e os Princípios do Direito: a questão das quotas raciais para ingresso no ensino superior no Brasil. Rio de Janeiro: Lumen Juris, 2006. p. 171-172.

${ }^{62}$ Disponível em <http://www.planalto.gov.br/ccivil_03/LEIS/L9504.htm>. Acesso em 11 nov. 2015

${ }^{63}$ Disponível em <http://www.planalto.gov.br/ccivil_03/leis/L9100.htm> Acesso em 11 nov 2015

${ }^{64}$ Disponível em <http://www.un.org/womenwatch/daw/cedaw/text/econvention.htm>. Acesso em 11 nov. 2015.
} vol.10, n. 03, Rio de Janeiro, 2017.pp. 1610-1632 
garantir a presença daqueles que possuem a identidade do grupo subalterno. ${ }^{65}$

No campo empresarial, o contexto apresentado é o de que, em que pese as mulheres exerçam cada vez mais atividades remuneradas, persiste o chamado "teto de vidro" em seu desfavor, i.e., "barreiras invisíveis" existentes em razão da aceitação de papéis masculinos e femininos e de suas normas implícitas de conduta que atuam de modo prejudicial às mulheres, impedindo ou dificultando a ascensão da mulher executiva aos altos cargos. ${ }^{66}$ Essas barreiras reforçam e são reforçadas pelos estereótipos de gênero, vedando que mulheres ocupem cargos de liderança cuja remuneração é melhor, bem como desestimulam ou impedem que elas persigam certas carreiras. ${ }^{67}$

Observou-se que há pesquisas apontando muitas evidências das ações discriminatórias, desde a composição do quadro de funcionários até a apuração dos méritos e reconhecimento do trabalho realmente exercido, especialmente onde inexistem políticas inclusivas. Em contrapartida, verifica-se a tendência ao reconhecimento da importância dos programas de ações afirmativas por parte do empregador, no sentido de evitar a perda de candidatos e empregados devidamente qualificados. ${ }^{68}$

Assim, do ponto de vista da igualdade material entre gêneros, o contexto laboral (público e privado) revela inúmeros desafios: uns mais objetivos, tal como remuneração igual para trabalho de mesma natureza, e outros mais subjetivos, quanto ao comportamento de seus integrantes e os estereótipos e padrões de comportamento que permanecem dificultando a ascensão feminina. É justamente nesse contexto que se insere o Projeto de Lei registrado sob no 112/2010, com tramitação no Senado Federal, dispondo sobre a participação de mulheres nos conselhos de administração das empresas públicas, sociedades de economia mista e respectivas subsidiárias $\left(\right.$ art. $1^{\circ}$ ), aumentando o percentual de participação destas nos conselhos deliberativos de maneira progressiva, com o fito de alcançar, ao fim, $40 \%$ de representação feminina na composição desses órgãos. ${ }^{69} \mathrm{O}$ projeto, ainda em discussão, essencialmente estabelece tais percentuais, porém não prevê sanções o seu descumprimento, deixando grande margem de especificação para edição de futuro regulamento (art. $4^{\circ}$ ).

A exposição de motivos do projeto sustenta o atendimento aos princípios presentes na constituição

\footnotetext{
${ }^{65}$ MIGUEL, L. F. Gênero e representação política. In: Miguel, L. F. e BIROLI, F. Feminismo e Política: uma introdução. 1. ed. São Paulo: Boitempo, 2014.p. 100.

${ }^{66}$ LIMA, Gustavo Simão, et al. O teto de vidro das executivas brasileiras. Revista Pretexto, Belo Horizonte, Vol.14(4), 2013 , p.66. $\mathrm{Na}$ análise desenvolvida pelos autores, foi realizado o estudo múltiplo de casos, com enfoque em duas grandes empresas brasileiras, uma do setor siderúrgico e outra do setor automobilístico, com o propósito de "identificar e analisar os principais desafios da carreira das mulheres executivas (presidentes, vice-presidentes, diretoras e gerentes de $3^{\circ}$ nível, logo abaixo das diretoras) no Brasil”. p.67

${ }^{67}$ BERKELEY, R. L. Gender based affirmative action: a journey that has only begun. Washington Journal of Urban and Contemporany Law, 1996. p. 365.

${ }^{68}$ BERKELEY, Rebecca L. Gender based affirmative action: a journey that has only begun. Washington Journal of Urban and Contemporany Law, 1996. p 366

${ }^{69}$ BRASIL. Projeto de Lei do Senado no 112, de 2010. Disponível em <http://www25.senado.leg.br/web/atividade/materias//materia/96597>. Acesso em 11 nov. 2015.
} 
brasileira e nas convenções internacionais, atentando para "a necessidade da inclusão feminina para que haja a devida correspondência entre a participação das mulheres na produção dos bens públicos e sua presença nos órgãos que decidem os destinos dos recursos produzidos a partir do esforço de toda a sociedade" ${ }^{70}$

A implementação deste tipo de ação afirmativa, na modalidade de cotas, embora, por conceito, seja de natureza temporária, passa por críticas recorrentes, tais como afronta ao princípio da igualdade, à apuração do mérito individual, bem como a perpetuação e geração de mais preconceitos e estigmas de acordo com sua posição social, acesso à educação, raça, orientação sexual, etc. - além do próprio questionamento se há, de fato, um conjunto de interesses identificável como femininos.

Entretanto, ao que parece, o mérito da sua aplicação reside justamente em que as ações afirmativas significam uma reformulação dos critérios de inserção das mulheres nos meios laborais, ou seja, seu principal efeito é a abertura de espaços institucionalmente fechados às mulheres. Além disso, independentemente da efetividade da medida - o que somente poderá ser aferido após sua implementação -, sua adoção nos parece legitimada pelo contexto antes apresentado, em que se verifica a permanência de uma estrutura que ainda carece de transformações apesar da (bastante lenta) evolução desde as primeiras manifestações da luta feminina por ocasião da Revolução Francesa.

Atingir o ideal de equidade entre homens e mulheres exige, pois, a reformulação das estruturas nas quais a sociedade funda suas bases. Pode-se questionar se as ações afirmativas seriam o caminho para tanto, uma vez que, como vimos, a mera detenção de uma posição política não implica, necessariamente, o real capital social e político pressupostos para que a atuação profissional feminina seja plena (principalmente em cargos de poder e prestígio). No entanto, presente o predomínio masculino nos cargos decisórios, verifica-se que a adoção das ações afirmativas para essa inserção mais justa e igualitária é perfeitamente razoável.

Trata-se, por fim, não de eleger um caminho único para o tratamento das iniquidades de gênero, mas sim de empregar os instrumentos jurídicos disponíveis ao poder público não só para colocar ao alcance das mulheres as posições sociais já definidas pelo viés masculino, mas também para o fim último de tornar possível, por meio dessa inserção, o questionamento da própria maneira como essas instituições se organizam e se definem. O certo é que, a ausência de tais medidas em nada contribuirá para a melhoria da posição das mulheres nos espaços a que tem direito. Muito pelo contrário, a omissão estatal neste tema tenderia a agravá-la.

70 BRASIL. Projeto de Lei do Senado no 112, de 2010. Justificação. Disponível em <http://www25.senado.leg.br/web/atividade/materias/-/materia/96597>. Acesso em 11 nov. 2015. 


\title{
WOMEN'S DISCRIMINATION IN BRASIL AND THE LEGITIMACY OF GENDER AFFIRMATIVE MEASURES
}

\begin{abstract}
The present work aims at analyzing the data that justify the adoption of quotas for women in the market and in the Brazilian political system, as other measures to fight gender iniquities. The inequalities originated from the model of society which has, as a rule, the male parameter, were historically discussed by the feminist movement trends, turning this debate into legal instruments to promote equal rights. Due to the permanence of inequalities concerning remuneration, household division of labor and autonomy, practices and public policies arise to promote material equality through a greater inclusion of women in labor and political environments. However, any considerations on the criticisms that are usually directed to the adoption of quotas presume the understanding of the context that causes and legitimates it, which is precisely the approach in this research.
\end{abstract}

Keywords: Feminism. Gender Discrimination. Equality. Affirmative action. Quotas for women.

\section{REFERENCIAS}

ANDREUCCI, Ana Claudia Pompeu Torezan. Igualdade de Gênero e ações afirmativas: desafios e perspectivas para as mulheres brasileiras pós Constituição Federal de 1988. São Paulo: LTr, 2012.

BRASIL. Presidência da República Secretaria de Políticas para as Mulheres. Relatório Anual socioeconômico da Mulher. 1ªmpressão. 2015.

BARZOTTO, Luis Fernando. Justiça Social - Gênese, estrutura e aplicação de um conceito. In: Revista da Procuradoria-Geral do Município de Porto Alegre. Porto Alegre: CEDIM: Unidade Editorial da Secretaria Municipal da Cultura, n.17, out.2003, p. 15-56

BELLINTANI, Leila Pinheiro. Ação Afirmativa e os Princípios do Direito: a questão das quotas raciais para ingresso no ensino superior no Brasil. Rio de Janeiro: Lumen Juris, 2006.

BERKELEY, Rebecca L. Gender based affirmative action: a journey that has only begun. Washington Journal of Urban and Contemporany Law. p. 353-368, 1996

BLANCO, Eglé Íturbe de. Women: Power and Development in Latin America. University of St. Thomas. Vol .5:3, 2008. pg. 675-697.

BOLOGNESI, Bruno. A cota eleitoral de gênero: política pública ou engenharia eleitoral? Paraná Eleitoral, Curitiba.v. 1 n. 2 p.113-129.

CRUZ, Alvaro Ricardo de Souza. O Direito à Diferença. Belo Horizonte: Arraes. 2009.

HENRY, P.J. Institucional Bias, In: DOVIDIO, John F. (Org.), The Sage Handbook of Prejudice, Stereotyping vol.10, no. 03, Rio de Janeiro, 2017.pp. 1610-1632 
and Discrimination. Londres: Sage, 2010.pg. 426-440

KAUFMANN, Roberta Fragoso Menezes. Ações afirmativas à brasileira: necessidade ou mito? Uma análise histórico-jurídico-comparativa do negro nos Estados unidos da América e no Brasil. Porto Alegre, Livraria do Advogado, 2007.

LANGE, Sacha E. de. Toward Gender Equality: Affirmativa Action, Comparable Worth, and the Women's. Movement. NYU Review of Law \& Social Change. Vol.31 pg. 315 - 360.

LIMA, Gustavo Simão; et al. O teto de vidro das executivas brasileiras. Revista Pretexto, Belo Horizonte, Vol.14(4), 2013, p.65-80.

LOPES, Cristiane Maria Sbalqueiro. Direito do trabalho da mulher: da proteção à promoção. Cadernos Pagu, ed. 26, p. 405-430, 2006.

LOVELL, Peggy A. Raça e gênero no Brasil. Lua Nova, n.35, p. 39-71, 1995. Tradução de Rafael Castro de Andrade.

MIGUEL, Luis Felipe. Teoria Política Feminista e Liberalismo: o caso das cotas de representação. Rev. Brasileira de Ciências Sociais, vol. 15, nº44, p.91-102, 2000.

MIGUEL, Luis Felipe, BIROLI, Flávia. Feminismo e política: uma introdução. 1aed. São Paulo: Boitempo, 2014. O'MELVENY, Mark K.. Playing the "Gender" Card: affirmative action and working women. Kentucky Law Journal, vol. 84, pg. 863-901,1995-1996.

PRA, Jussara Reis, EPPING, Léa. Cidadania e feminismo no reconhecimento dos direitos humanos das mulheres. Revista Estudos Feministas, vol.20(1), p.33-51, 2012.

Mulheres, direitos políticos, gênero e feminismo. Cadernos Pagu, Campinas, no43, p. 169-196, 2014.

RIOS, Roger Raupp. Direito da Antidiscriminação: discriminação direta, indireta e ações afirmativas. Porto Alegre, Livraria do Advogado, 2008.

RIOS, Roger Raupp:; SILVA, R. da. Discriminação múltipla e discriminação interseccional: aportes do feminismo negro e do direito da antidiscriminação. Revista Brasileira de Ciência. Política,n. 16, p. 11-37, 2015.

SHEPPARD, Colleen. Equality Rights and Institutional Change: Insights from Canada and the United States. Arizona Journal of International and Comparative Law, v.15, p.143-167,1998.

SOWELL, Thomas. Ação afirmativa ao redor do mundo: um estudo empírico. Rio de Janeiro: UniverCidade, 2004.

Trabalho enviado em 10 de fevereiro de 2017.

Aceito em 14 de abril de 2017. 